\title{
KONTROL KUALITAS POLI GIGI DI RS PKU DELANGGU MENGGUNAKAN ANALISA SWOT
}

\author{
Morita Sari $^{1}$, Ichda Nabiela Amiria Asykarie ${ }^{2}$ \\ ${ }^{1,2}$ Fakultas Kedokteran Gigi, Universitas Muhammadiyah Surakarta. Jl. Kebangkitan \\ Nasional No.101, Penumping, Laweyan, Penumping, Laweyan, Kota Surakarta, Jawa \\ Tengah 57141 \\ Email: ${ }^{1}$ morita.sari@ums.ac.id, ${ }^{2}$ nabiela.ameer@gmail.com
}

\begin{abstract}
ABSTRAK
Pembangunan kesehatan mempunyai tujuan agar setiap masyarakat mampu hidup sehat. Sesuai dengan Kep Menkes RI Nomor 129/Menkes/SK/II/2008, rumah sakit sebagai salah satu fasilitas pelayanan kesehatan bertanggung jawab untuk menyediakan pelayanan kesehatan dan meningkatkan kesehatan masyarakat. Fasilitas poli gigi adalah salah satu jenis pelayanan yang harus ada di rumah sakit, namun hanya sedikit poli gigi yang bertempat di rumah sakit mempunyai kualitas pelayanan prima. Analisa mengenai kualitas pelayanan khususnya di poli gigi yang bertempat di rumah sakit sangat jarang dilakukan sebab poli gigi kebanyakan hanya bersifat pelengkap. Untuk mengevaluasi kualitas pelayanan poli gigi di RS PKU Muhammadiyah Delanggu. Penelitian ini merupakan penelitian observational yang dilakukan di RS PKU Muhammadiyah Delanggu sebagai bentuk evaluasi dari pelayanan poli gigi rumah sakit menggunakan metode analisa SWOT. Analisa kualitas pelayanan dapat dilakukan setelah kita mengetahui akar permasalahan yang ada dalam pelayanan kesehatan tersebut. Poli gigi di RS PKU Muhammadiyah Delanggu memiliki beberapa permasalahan yang berkaitan dengan fasilitas yang disediakan oleh rumah sakit. Kondisi ini menyebabkan kinerja yang kurang optimal dalam pelayanan kesehatan gigi. Analisis SWOT merangkum faktor internal dan eksternal yang dapat mempengaruhi masa depan poli gigi. Analisis ini memberikan cara yang sederhana untuk merumuskan beberapa strategi untuk meningkatkan kualitas pelayanan poli gigi di RS PKU Muhammadiyah Delanggu. Kinerja pelayanan poli gigi di RS PKU Muhammadiyah Delanggu masih kurang efektif dan optimal, sehingga memerlukan perbaikan fasilitas untuk dapat meningkatkan kualitas pelayanan.
\end{abstract}

Kata Kunci: Rumah Sakit, Poli gigi, Kualitas, SWOT

\begin{abstract}
The goal of health development is increasing community health status. According to Kepmenkes RI Nomor 129/Menkes/SK/II/2008 hospital as one of health service facilities had responsibility to provide health service and increasing population health. Dental clinic is one of the facilities that the hospital should have but only few dental clinic in
\end{abstract}


hospital have top service quality. The analysis about quality control for dental clinic in hospital is rare. It is because dental clinic in hospital is an auxiliary in the hospital organization. To evaluate service quality of dental clinic at RS PKU Muhammadiyah Delanggu. This is an observational research at RS PKU Muhammadiyah Delanggu. We did program evaluation for Dental Clinic in hospital using SWOT analysis. Analysis of service quality can be done after we know the problem root in that health service. Dental clinic at PKU Delanggu Muhammadiyah Hospital had some problems related to the facilities provided by the hospital. This condition causing less optimal performance of dental health service. SWOT analysis summarizes the most important internal and external factors that may affect the future of dental clinic. This analysis provides a simple way to formulate some strategy to improve the service quality of dental clinic at PKU Delanggu Muhammadiyah Hospital. Service of dental clinic at RS PKU Muhammadiyah Delanggu still less effective and optimum performance, so require upgrading of facilities to improve the service quality.

Keywords : Hospital, Dental Clinic, Quality, SWOT

\section{PENDAHULUAN}

Sistem kesehatan nasional memiliki tujuan untuk mencapai kemampuan hidup sehat melalui upaya perbaikan dan peningkatan kualitas pelayanan rumah sakit (Aditama, 2003). Pelayanan kesehatan yang berkualitas adalah pelayanan kesehatan yang dapat memberikan kepuasan terhadap pasien dan sesuai dengan standar pelayanan yang ditetapkan dalam pelaksanaan pelayanannya (Supriyatno dan Anni, 2014).

Kualitas pelayanan dalam sebuah pelayanan kesehatan sangatlah penting untuk mewujudkan kepuasan pelanggan. Persaingan yang semakin kuat dalam sebuah lingkungan seharusnya menjadi salah satu hal yang membuat sebuah rumah sakit memiliki kesadaran tentang pentingnya memberikan kualitas pelayanan yang terbaik bagi para pelanggannya (Arab dkk., 2015).

Kepuasan pelanggan merupakan faktor penting dalam menentukan keberhasilan dan kelangsungan hidup jangka panjang sebuah pelayanan kesehatan yang semakin kompetitif (Laohasirichaikul dkk., 2010). Tingkat kepuasan pelanggan atas pelayanan yang diberikan rumah sakit dapat mengurangi jumlah keluhan pasien, meningkatkan jumlah kunjungan pasien dan dapat meningkatkan profitabilitas (Wu, 2011).

Berdasarkan Kepmenkes RI Nomor 129/Menkes/SK/II/2008, rumah sakit adalah sarana kesehatan yang menyelenggarakan pelayanan kesehatan perorangan meliputi pelayanan promotif, preventif, kuratif dan rehabilitatif yang menyediakan pelayanan rawat inap, rawat jalan dan gawat darurat. Rumah sakit juga memiliki peran yang strategis dalam meningkatkan derajat kesehatan masyarakat, oleh karena itu rumah sakit dituntut untuk memberikan pelayanan yang bermutu sesuai dengan standar yang ditetapkan dan dapat menjangkau seluruh lapisan masyarakat (Kemenkes RI, 2008).

Rumah Sakit PKU Muhammadiyah Delanggu merupakan salah satu rumah sakit swasta milik yayasan Muhammadiyah. Meskipun rumah sakit 
swasta namun rumah sakit ini berusaha memberikan pelayanan kesehatan secara professional. Persaingan dari providerprovider yang lain membuat pihak Rumah Sakit PKU Muhammadiyah Delanggu dituntut untuk selalu memperbaiki kinerjanya agar dapat menambah kepercayaan masyarakat atas pelayanan kesehatan yang diberikan. Kepercayaan ini sangat penting sebab masyarakat merupakan pengguna jasa utama. Peningkatan kepercayaan masyarakat terhadap rumah sakit di harapkan akan berbanding lurus pada pendapatan rumah sakit serta perbaikan kinerja secara menyeluruh.

Pelayanan kesehatan gigi dan mulut adalah salah satu pelayanan yang harus tersedia di sebuah rumah sakit (Kumalasari, 2013). Pemerintah dan pemerintah daerah wajib menjamin ketersediaan tenaga, fasilitas pelayanan, alat dan obat kesehatan gigi dan mulut dalam rangka memberikan pelayanan kesehatan gigi dan mulut yang aman, bermutu, dan terjangkau oleh masyarakat (UU RI No. 36 Tahun 2009 Pasal 94).

Rumah Sakit PKU Muhammadiyah Delanggu merupakan salah satu rumah sakit yang menyediakan pelayanan gawat darurat, rawat inap, maupun pelayanan rawat jalan. Salah satu pelayanan rawat jalan yang ada di Rumah Sakit PKU Muhammadiyah Delanggu adalah pelayanan kesehatan gigi dan mulut, yaitu poli gigi yang sudah ada sejak tahun 2005 . Undang-Undang (UU) nomor 36 tahun 2009 tentang kesehatan menekankan pentingnya upaya peningkatan mutu pelayanan kesehatan. Mutu pelayanan adalah sejauh mana sebuah pelayanan kesehatan mampu memberikan layanan sesuai dengan standar operasional prosedur (Mukti dan Ali, 2007).

Mutu pelayanan kesehatan adalah tingkat derajat terpenuhinya kebutuhan masyarakat atau perorangan terhadap layanan kesehatan yang sesuai dengan standar profesi yang baik dengan pemanfaatan sumber daya secara wajar, efisien, efektif, aman dan memuaskan pelanggan sesuai dengan norma dan etika yang baik (Bustami, 2011).

Menurut beberapa penelitian yang meneliti tentang hubungan kualitas pelayanan kesehatan dengan harapan pasien dan persepsi tentang kualitas didapatkan bahwa kualitas suatu pelayanan adalah kemampuan untuk memenuhi harapan pasien atau pelanggan (Pui-Mun Lee, 2006). Salah satu komponen penting dari kualitas pelayanan kesehatan adalah kepuasan pasien (Saila, 2008). Semakin baik tingkat kepuasan pasien, maka semakin baik pula kualitas pelayanan kesehatan tersebut (Lai dkk., 2009).

Persepsi yang positif mengenai kualitas pelayanan mempengaruhi keputusan pasien untuk memilih sebuah pelayanan kesehatan. Maka dari itu penting bagi sebuah pelayanan kesehatan untuk meningkatkan kualitas dari pelayanannya (Andaleeb, 2001).

Kepuasan pasien, kualitas pelayanan dan efisiensi dalam pengelolaan menjadi "holy trinity" sebuah pelayanan kesehatan saat ini yang berorientasi pada pasien dan bertujuan untuk meningkatkan kualitas. Penerapan dari kualitas pelayanan kesehatan tidaklah mudah karena karena tingkat kepuasan pasien bersifat subjektif dan berbeda bagi setiap orang (Visnjic dkk., 2012).

Setiap organisasi akan dihadapkan dengan berbagai faktor baik internal maupun eksternal yang di satu sisi hal ini dapat menjadi stimulus, dan disisi lain dapat menjadi suatu ancaman terhadap kinerja dan tujuan yang ingin dicapai oleh organisasi (Oreski, 2012).

Rumah Sakit PKU Muhammadiyah Delanggu memiliki pelayanan poli gigi yang sudah ada kurang lebih 11 tahun. Selama kurun waktu tersebut belum 
pernah dilakukan evaluasi mengenai kinerja dan kualitas pelayanan poli gigi. Selain itu, sering pula ditemukan pelayanan yang sekalipun dinilai telah memuaskan pasien, namun ketika dievaluasi dari standar pelayanan profesi ternyata kinerjanya masih belum terpenuhi secara optimal. Untuk itu dalam penerapan kualitas pelayanan kesehatan gigi di rumah sakit ini dibutuhkan adanya suatu analisis yang dapat menggambarkan dan mengidentifikasi situasi yang sedang dihadapi oleh poli gigi baik dari sisi internal maupun eksternal.

Analisis yang dapat dilakukan adalah analisis SWOT (Strength, Weakness, Opportunity and Threat). Analisis SWOT merupakan suatu alat yang cukup penting yang berfungsi untuk membantu mengambil keputusan dan sering digunakan sebagai alat untuk menganalisa organisasi secara sistematis, baik dari segi faktor internal maupun eksternal yang terdapat pada sebuah organisasi (Yuksel dan Dagdeviren, 2007).

Penelitian ini dilaksanakan pada bulan September 2016 dan bertujuan untuk mengevaluasi kualitas pelayanan poli gigi di Rumah Sakit PKU Muhammadiyah Delanggu dengan mengidentifikasi permasalahan apa saja yang terdapat pada pelayanan, serta menganalisis faktor internal maupun eksternal yang dapat berpengaruh terhadap kinerja poli gigi. Hasil analisis tersebut akan diolah menjadi sebuah keputusan strategi untuk meningkatkan kualitas pelayanan poli gigi di rumah sakit tersebut.

Metode yang digunakan dalam penelitian ini adalah metode penelitian observational dengan pendekatan kualitatif, yaitu dengan menguraikan dan menganalisis fakta yang ada untuk menunjang keterangan yang diperlukan dalam penelitian.
Data yang dikumpulkan bersifat kualitatif diperoleh dengan melakukan observasi langsung di lapangan dan interview terhadap narasumber yang dianggap mampu memberikan informasi yang dibutuhkan.

Data yang diperoleh dianalisis secara kualitatif dan dibagi kedalam matrik factor strategi internal dan matrik factor strategi eksternal. Kemudian hasilnya dimasukkan dalam model kuantitatif, yaitu matrik SWOT untuk merumuskan dan menetapkan strategi kompetitif organisasi.

\section{DISKUSI}

Analisis kualitas pelayanan dapat dilakukan setelah kita mengetahui akar permasalahan yang ada di pelayanan tersebut. Pada penelitian ini telah dilakukan observasi di poli gigi RS PKU Muhammadiyah Delanggu. Dari hasil observasi berupa wawancara dengan narasumber, ditemukan beberapa permasalahan di poli gigi seperti :

a.

idak memiliki dokter gigi tetap, sehingga jadwal pelayanan poli gigi hanya dilayani pada sore hari pukul 57.

b.

elayanan poli gigi di rumah sakit ini hanya memiliki dua dokter gigi sebagai dokter tamu dan tidak memiliki dokter spesialis, sehingga apabila ada pasien yang tidak dapat ditangani oleh dokter gigi jaga dan harus ditangani oleh dokter gigi spesialis maka akan di rujuk ke rumah sakit lain yang memiliki pelayanan dokter gigi spesialis.

c.

idak memiliki perawat gigi, sehingga dokter gigi harus secara mandiri melakukan pelayanan seperti memanggil urutan antrian pasien untuk masuk ke ruang periksa, mempersiapkan alat dan bahan, 
hingga membereskan alat dan bahan habis pakai.

d.

ental unit yang dimiliki oleh poli gigi dirasa tidak cukup memadai, dikarenakan umur dental unit tersebut sudah cukup lama dan tidak cukup terawat sehingga ada beberapa bagian dari dental unit yang sudah tidak berfungsi dan mempengaruhi kinerja dokter gigi dalam memberikan pelayanan pasien.

e.

urangnya peralatan di poli gigi, dikarenakan tidak adanya upgrade dari rumah sakit untuk poli gigi sejak tahun 2005.

f.

ekam medis yang masih manual dan tidak terdapat odontogram, sehingga ketika terjadi missing file dan digantikan dengan rekam medis baru, dokter gigi kesulitan untuk menemukan riwayat medis maupun hasil pemeriksaan penunjang yang disimpan di dalam catatan rekam medis yang lama, sehingga menyebabkan tidak optimalnya pelayanan di poli gigi.

g.

idak adanya alat sterilisasi di dalam ruang poli gigi, sehingga alat yang telah dipakai dan dibersihkan tidak bisa segera di sterilisasi.

h.

danya keluhan pasien disebabkan waktu antri yang terlalu lama.

i.

lat suction sudah tidak berfungsi, sehingga dapat memperlama waktu perawatan karena pasien harus selalu berkumur. j.

elas kumur yang digunakan di poli gigi tidak disposibel, masih menggunakan gelas yang dicuci dan menggunakan air dari keran wastafel untuk berkumur.
Dari permasalahan-permasalahan di atas dapat ditelusuri akar penyebab masalah..seperti..yang.di.tampillkanDdalam diagram Fish Bone Ishikawa adalah sebagai berikut ini :

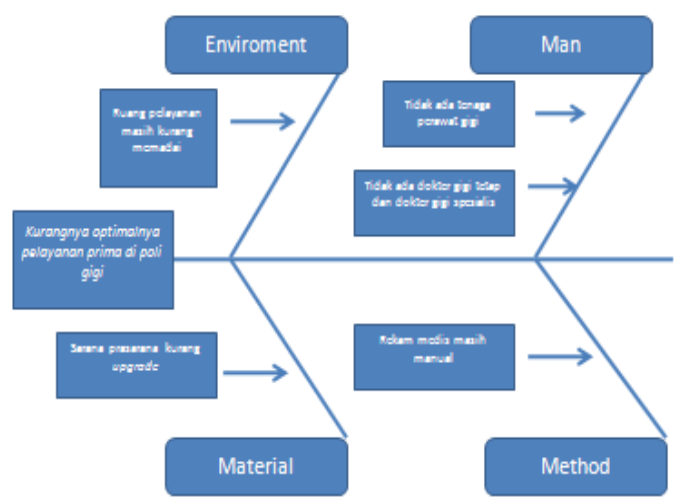

Gambar $1:$ Fishbone Ishikawa

\section{Penetapan Prioritas Masalah di Poli Gigi Rumah Sakit}

Berdasarkan hasil dari wawancara dengan salah satu dokter gigi jaga di poli gigi Rumah Sakit PKU Muhammadiyah Delanggu, didapatkan beberapa permasalahan yang terjadi di poli gigi rumah sakit tersebut yang dapat menyebabkan kurang optimalnya .pelayanan...di...poli...gigi,...dari...beberapa permasalahan tersebut ditemukan satu akar permasalahan yang paling diprioritaskan untuk dilakukan penyelesaian yaitu kurangnya upgrade sarana.dan.prasarana.y.ang .terdapat Ali poli gigi karena menurut DepKes RI tahun 2004, peralatan di poli gigi rumah sakit wajib. disediakan. sesuai.standar. pelAyanan untuk melaksanakan pelayanan kesehatan gigi sehingga dapat meningkatkan mutu pelayanan kesehatan gigi di rumah sakit (Depkes RI, 2004).

\section{Analisis SWOT Poli Gigi di Rumah Sakit}

Analisis SWOT adalah sebuah alat perencanaan strategis yang klasik dengan 
menggunakan kerangka kerja dari faktor internal maupun eksternal. Alat ini memberikan cara yang sederhana untuk memperkirakan jalan keluar terbaik dalam merumuskan strategi suatu organisasi (Jackson dkk., 2003). SWOT merupakan salah satu metode analisis manajemen yang luas dan merupakan instrumen atau alat yang digunakan untuk mengambil serta memutuskan suatu strategi (Kurttila dkk., 2000).

Analisis SWOT digunakan sebagai alat untuk mencapai pendekatan sistematis dan mengatasi suatu situasi. Faktor internal maupun eksternal ini sangat penting diketahui untuk kelangsungan masa depan suatu organisasi, hal ini disebut sebagai faktor strategi dan disajikan dalam matrik SWOT (Oreski, 2012). Analisis ini berdasarkan pada logika yang dapat memaksimalkan kekuatan (strength) dan peluang (opportunities), sekaligus secara bersamaan dapat meminimalkan kelemahan (weakness) dan ancaman (threats). Keputusan strategis dalam sebuah organisasi perlu mempertimbangan faktor internal yang mencakup kekuatan dan kelemahan maupun faktor eksternal yang mencakup peluang dan ancaman (Dyson, 2004).

Proses pengambilan keputusan strategi selalu berkaitan dengan pengembangan misi, tujuan, strategi dan kebijakan organisasi. Dengan demikian, perencanaan strategi harus menganalisa faktor-faktor strategi dalam kondisi yang ada saat ini. Analisis SWOT membandingkan antara faktor eksternal peluang dan ancaman dengan faktor internal kekuatan dan kelemahan. Faktor internal dimasukan kedalam matrik yang disebut matrik faktor strategi internal atau IFAS (Internal Strategic Factor Analisis Summary). Faktor eksternal dimasukkan kedalam matrik yang disebut matrik faktor strategi eksternal EFAS (Eksternal Strategic Factor Analisis Summary). Setelah matrik faktor strategi internal dan eksternal selesai disusun, kemudian hasilnya dimasukkan dalam model kuantitatif, yaitu matrik SWOT untuk merumuskan strategi kompetitif organisasi (Freddy, 2004).

Tabel 1. Tabel Matriks Analisa SWOT

\begin{tabular}{ccc}
\hline & Strength & Weaknesses \\
\hline Oppoturnities & Strategi SO & Strategi WO \\
Threats & Strategi ST & Strategi WT \\
\hline
\end{tabular}

Dari pengumpulan data berupa hasil interview dan observasi langsung maka dilakukan analisis SWOT di poli gigi Rumah Sakit PKU Muhammadiyah Delanggu. Pemetaan analisis di tampilkan dalam bentuk Tabel seperti yang di tampilkan di Annex. 1 dengan penjelasan sebagai berikut :

a.

aktor Internal

Strength (Kekuatan)

1.

emiliki dua dokter gigi yang terbagi dalam dua jadwal jaga yang berbeda.

2.

erada di rumah sakit swasta yang memiliki sumber dana secara mandiri tanpa melalui pemerintah.

Weakness (Kelemahan)

1 ......

arana prasarana poli gigi yang masih kurang memadai dan kurang upgrade.

2. urangnya SDM seperti perawat 
gigi dan tidak memiliki dokter gigi tetap maupun spesialis.

$\mathrm{b}$

aktor Eksternal

Opportunities (Peluang)

Poli gigi berada di rumah sakit yang merupakan PPK / Faskes tingkat II sehingga banyak menerima rujukan dari PPK / Faskes tingkat I di wilayah kerjanya.

\section{Threats (Ancaman)}

1. asilitas yang kurang berkembang sehingga menyebabkan mutu pelayanan kurang optimal.

2.

umah sakit lain di wilayah sekitar

Rumah Sakit

PKU

Muhammadiyah Delanggu sudah memiliki SDM dan fasilitas yang lebih memadai.

Kemudian matrik SWOT untuk menentukan rencana strategis adalah :

\section{$\underline{\text { SO Strategi }}$}

Memfasilitasi kebutuhan poli gigi rumah sakit dan memaksimalkan jadwal jaga sekaligus meningkatkan retensi bagi dua dokter gigi yang sudah ada seperti mengikutkan pelatihan maupun seminar untuk meningkatkan kompetensi.

\section{WO Strategi}

Melengkapi sarana dan prasarana poli gigi yang masih kurang memadai dan tidak upgrade, serta merekrut tenaga perawat gigi agar kinerja dan pelayanan di poli gigi lebih optimal dan efektif.

\section{$\underline{\text { ST Strategi }}$}

Anggaran dana untuk mengembangkan sarana dan prasarana poli gigi dapat dioptimalkan seping dapat meningkatkan mutu pelayanan poli gigi rumah sakit.

\section{WT Strategi}

Menambah SDM seperti perawat gigi maupun dokter gigi spesialis, serta melakukan upgrading sarana dan prasarana sehingga fasilitas di poli gigi dapat bersaing dengan poli gigi rumah sakit lain di sekitarnya yang memiliki fasilitas yang lebih memadai.

\section{Prioritas - *Terhadap · Eangkah-Edngkah Pemecahan Masalah.}

Dari hasil analisis menggunakan metode analisis SWOT didapat beperapa strategi yang dapat segera dilaksanakan agar permasalahan yang terdapat di pelayanan kesehatan gigi Rumah Sakit PKU Muhammadiyah Delanggu dapat segera teratasi, prioritas dari langkahlangkah pemecahan masalah adalah sebagai berikut :

1.

emfasilitasi kebutuhan poli gigi serta melengkapi sarana prasarana yang masih kurang upgrade agar mutu pelayanan di poli gigi dapat lebih dioptimalkan.

2 .

erekrut tenaga perawat gigi untuk membantu tugas dokter gigi agar kinerja dan pelayanan di poli gigi dapat lebih efektif dan efisien dalam memberikan pelayanan kesehatan gigi kepada pasien.

3.

erekrut dokter gigi tetap agar pelayanan kesehatan gigi di rumah 
sakit juga dapat dilayani pada waktu pagi maupun siang hari. 4

enambah pelayanan poli gigi spesialis sehingga poli gigi rumah sakit dapat bersaing dengan rumah sakit lain disekitarnya yang memiliki fasilitas pelayanan yang lebih memadai.

\section{KESIMPULAN}

Berdasarkan hasil analisa di poli gigi Rumah Sakit PKU Muhammadiyah Delanggu menggunakan metode analisis SWOT dapat disimpulkan bahwa pelayanan kesehatan gigi yang berada di rumah sakit ini merupakan fasilitas kesehatan tingkat kedua yang banyak menerima rujukan dari fasilitas tingkat pertama tetapi dalam pelayanannya poli gigi ini masih memiliki banyak kekurangan seperti tidak adanya dokter gigi tetap maupun dokter gigi spesialis dan hanya memiliki dua tenaga medis dokter gigi sebagai dokter gigi tamu yang melakukan pelayanan pasien hanya pada sore hari. Selain itu unit pelayanan kesehatan gigi ini tidak memiliki perawat gigi yang dapat membantu tugas dokter gigi sehingga menyebabkan kurang efektifnya pelayanan pasien. Sarana dan prasana yang terdapat di poli gigi juga masih kurang upgrade sehingga menyebabkan kurang optimalnya kyalitas pelayanan kesehatan gigi yang diberikan kepada pasien.

\section{SARAN}

Ada beberapa hal yang dapat disarankan untuk kemajuan poli gigi di Rumah Sakit PKU Muhammadiyah Delanggu, yaitu :

1. Segera dilakukan perbaikan dan pengembangan fasilitas yang ada di poli gigi agar pelayanan kesehatan gigi dan mulut dapat dilaksanakan secara optimal serta meningkatkan mutu pelayanan, sehingga kepuasan pasien pun dapat ditingkatkan.

2. Pelayanan kesehatan gigi ini berada di sebuah rumah sakit yang merupakan fasilitas kesehatan tingkat kedua yang menjadi rujukan pasien dari fasilitas kesehatan tingkat pertama, sehingga sangat diperlukannya peningkatan sarana dan prasana maupun penambahan tenaga medis agar keberadaannya dapat bersaing baik dengan pelayanan kesehatan gigi di rumah sakit sekitarnya.

\section{DAFTAR PUSTAKA}

Aditama, T., 2003, Manajemen Rumah Sakit, Penerbit Universitas Indonesia, Jakarta.

Andaleeb, S. S., 2001, Service quality perceptions and patient satisfaction : a study of hospitals in a developingcountry, Social Science \& Medicine, Vol. 52 : 13591370.

Arab, M., Marzban, S., Pouragha, B., Daneshkohan, A. dan Zarei, E., 2015, An Empirical Study of The Impact of Service Quality on Patient Satisfaction in Private Hospitals Iran, Global Journal of Health Science, Vol. 7 (1) : 1-9.

Bustami., 2011, Penjamin Mutu Pelayanan Kesehatan dan Akseptabilitasnya, Erlangga, Jakarta. 
Departemen Kesehatan RI, 2004, Pedoman Upaya Kesehatan Gigi Masyarakat, Kementerian Kesehatan Republik Indonesia, Jakarta.

Dyson, R., 2004, Strategic development and SWOT analysis at the University of Warwick, European Journal Of Operational Research, Hal : 631-640.

Freddy, Rangkuti., 2004, Analisis SWOT Teknik Membedah Kasus Bisnis, PT. Gramedia, Jakarta.

Jackson, S. E., Joshi, A. and Erhardt, N. L., 2003, Recent Research on Team and Organizational Diversity: SWOT Analysis and Implication, Journal of Management, Vol. 29 (6), Hal : 801-830.

Kemenkes RI, 2008, Peraturan Menteri Kesehatan Nomor 129 tentang Standar Pelayanan Minimal Rumah Sakit, Kementerian Kesehatan Republik Indonesia, Jakarta.

Kumalasari, C., 2013, Upaya Peningkatan Kunjungan Pasien Poli Gigi dengan Pendekatan Marketing 3.0, J. Adm. Kebijak. Kesehat., Vol. 11 (1) : 11-15.

Kurttila, M., Pesonen, M., Kangas, M. dan Kajanus, M., 2000, Utilizing the analytic hierarchy process AHP inSWOT analysis a hybrid method and its applicationto a forest-certification case, Forest Policy and Economics, Vol. 1: 41-52.

Lai, F., Griffin, M. dan Babin, B. J., 2009, How quality, value, image, and satisfaction create loyalty at a Chinese telecom, Journal of Business Research, Vol. 62 (10) : 980-986.

Laohasirichaikul, B., Chaipoopirutana, S. dan Combs, H., 2010, Effective customer relationship of health care: a study of hospitals in Thailand, Journal of Management and Marketing Research, Vol. 17 (1) : 1-12.

Mukti, Ali Ghufron, 2007, Strategi Terkini Peningkatan Mutu Pelayanan Kesehatan : Konsep Implementasi, PT. Karya Husada Mukti, Yogyakarta.

Oreski, D., 2012, Strategy development by using SWOT-AHP, TEM Journal, Vol 1 (4) : 283-291.

Pui-Mun Lee, P. K., 2006, Impact of Deficient Healthcare Service Quality, The TQM Magazine, Vol. 18 (6) : 563-571.

Saila, T. M. E., 2008, Measuring Patient Assessments of The Quality of Outpatient Care : A SystematicReview, Journal of Evaluation in Clinical Practice, Vol. 14: 148-154. 
Supriyanto, S. dan Anni R. U., 2014, Analisis Mutu Pelayanan Kesehatan Berdasarkan Dimensi Dabholkar Di Paviliun Mina Rumah Sakit Siti Khodijah Sepanjang, Jurnal Administrasi Kesehatan Indonesia, Vol. 2 (1) : 1 -12.

Undang-Undang Republik Indonesia Nomor 36 Tahun 2009 tentang Kesehatan Pasal 94, Lembaran Negara Republik Indonesia Tahun 2009 No. 5063,Jakarta : Sekertariat Negara.

Visnjic, A., Velickovic, V. dan Jovic, S., 2012, Measures for Improving the Quality of Health Care, Scientific Journal of the Faculty of Medicine in Niš, Vol. 29 (2) : 53-58.

Wu, C. C., 2011, The Impact of Hospital Brand Image on Service Quality Patient Satisfaction and Loyalty, African Journal of Business Management, Vol. 5 (12) : 4873-4882.

Yuksel, I., dan Dagdeviren, M., 2007, Using the analytic network process (ANP) in a SWOT analysis-A case study for a textile firm, Information Sciences, Vol. 177 : 3364-3382. 